\title{
A Study on the Biodegradation of Petroleum by a Novel Microbial Consortia
}

\author{
Arpan Chatterjee ${ }^{1}$, Ujjyani Ghosh ${ }^{1}$, Ishani Banerjee ${ }^{1}$, Sreeja Saha ${ }^{1}$, Monalisa \\ Barman $^{1}$, Ashadul Haque ${ }^{1}$, Arup Kumar Mitra ${ }^{1}$ \\ I'Post Graduate Department of Microbiology, St. Xavier's College, Kolkata, Affiliated to Calcutta University,
} India)

\begin{abstract}
Hydrocarbons enter into environment mainly via waste disposal, accidental spillage and leakage tankers. Hydrocarbon toxicity is caused by low boiling point aromatic hydrocarbons including benzene, toluene, xylene, naphthalene etc. and the toxicity is spread in almost all compartment of environment e.g., plants by damaging protoplast, animals by causing various lung diseases and cancers and atmosphere by decomposing the ozone layer and it can be prevented also by using hydrocarbon degrading microorganisms. In this investigation, at first 6 hydrocarbon degrading bacterial strains were isolated from oil contaminated soil near a petrol pump of petrochemical industries at Budge Budge, Kolkata. Their hydrocarbon degrading ability was checked by their ability to grow in mineral salt based Bushnell Haas medium supplemented with petrol as a sole carbon source. Along with gram characterization and different biochemical tests, their hydrocarbon tolerance level was measured, which was found to be up to 8\% for isolate 1, 3 and 4. The isolates were also examined for the activity of three different hydrocarbon degrading enzymes namely laccase, tyrosinase and catechol oxidase. It was found that isolate 3 had the highest activity for these enzymes and it could also degrade the petroleum to produce $\mathrm{CO}_{2}$ within 7 days. The isolate also had metal adhering ability by forming biofilm on it. From the colony morphology and microscopic analysis, it was presumed that isolate 3 was an actinobacteria, which was finally proved by their ability to grow in selective medium-starch casein agar and 16s rDNA sequencing and it was found that isolate 3 was Streptomyces bacillaris S4BW2. So these isolates seemed to have potential for bioremediation of hydrocarbon pollution and thus, can serve as a potential tool to degrade petroleum waste.
\end{abstract}

Keywords: Bushnell Haas medium, Catechol oxidase, $\mathrm{CO}_{2}$ evolution, Hydrocarbon tolerance, Laccase, Petroleum contamination, Streptomyces bacillaris S4BW2, Tyrosinase.

\section{Introduction}

Hydrocarbon degrading organisms are ubiquitously distributed in environment, comprising less than $1 \%$ of the total microbial community in terrestrial ecosystem. But under the influence of oil and hydrocarbon pollutants, the population of hydrocarbon degrading microbes rises to $10 \%$ of the community. The physical, chemical and biological factors that govern rate of hydrocarbon degradation by bacterial community include composition, state and concentration of oils and hydrocarbons in soil, absorptivity of soil particles, dispersion and emulsification enhancing rates of water content of soil, temperature, pressure, nutrient availability, salinity, $\mathrm{pH}$ and moisture content in soil [1]. In the eubacterial community, heterotrophs, polycyclic aromatic hydrocarbon (PAH) degraders and TPH degraders are persistent [2].

Soluble fractions of oil, comprising of low boiling point aromatic hydrocarbons like, benzene, touluene, xylene, napthalene, pentathrene etc., are the main sources of oil toxicity [3]. Microbes play major role in detoxification of toxic hydrocarbons to relatively non-toxic varieties, like carbon dioxide, water and biomass. Otherwise xenobiotic compounds exhibit carcinogenic, mutagenic and terratogenic effects on human population, which makes bioremediation of pollutants a bare necessity in modern era, where microbes mineralize, immobilize or transform toxic hydrocarbons to nontoxic products in a cost -effective, less time consuming and efficient manner.

Petroleum get into the environment by the events of waste disposal, accidental spills, leakage tankers and losses during transport or shortage [4]. The fuel is a complex mixture of normal, branched and cyclic alkenes, and aromatic compounds, which is obtained from the middle distillate fraction in the course of petroleum separation. The toxic effects of crude oil and refined petroleum oils on plants, humans and environment are dreadful [5].

Hydrocarbons in soil are initially attacked by oxygenases produced by soil microbiota, using oxygen as the second substrate. Degradation by peripheral pathways leads to production of $\mathrm{C} 2$ compounds that enter citric acid cycle to form C6 and C4 TCA cycle intermediate [6]. Carbon dioxide is produced as a byproduct along with hydrogen peroxide as a reaction intermediate, utilizing ammonium phosphate, sulfate and ferrous ions. Thus organisms increase in cell biomass using hydrocarbon as its sole carbon source. 
Bioremediation process depends on the hydrocarbon degrading ability of microbes, which are present naturally and are highly efficient due to their simplicity and cost effectiveness. Bioremediation is a process of using microorganisms to degrade toxic chemicals into organic chemicals, leading ultimately to the formation of carbon-dioxide, water and biomass [7].

This study was undertaken to gain insight into the concept of bioremediation by the isolation of bacteria growing in oil contaminated soils near petrol pumps of Petrochemical Industries in Kolkata which can degrade petroleum products. The experiment was further progressed to study the morphological and Gram characterization of the isolated organisms, biochemical testing such as IMVIC, Catalase and Oxidase, determination of sensitivity assay of the isolated organisms to different concentrations of petrol and kerosene, determination of the presence of hydrocarbon degrading enzymes such as laccase, monophenol oxidase like tyrosinase and polyphenol oxidase like catechol oxidase, determination and estimation of the amount of $\mathrm{CO}_{2}$ liberated by the organisms during degradation of petroleum and in the absence of petroleum, identification of the nature of the most efficient organism by growing it in a selective media and finally phylogenetic analysis of the most efficient organism by performing $16 \mathrm{~s}$ rDNA sequencing.

\subsection{Collection and Characterization of the soil sample}

\section{Materials and Methods}

Soil samples were collected from oil contaminated sites near petrol pump of Petrochemical Industries at Budge Budge, Kolkata. The samples were collected in sterile containers at a $5 \mathrm{~cm}$ depth from the surface of soil to avoid contamination. Collected samples were transferred to the laboratory under sterile condition for physical and chemical characterization like $\mathrm{pH}$ and water conductivity.

\subsection{Isolation of petroleum degrading bacteria}

$10 \mathrm{gm}$ of soil sample was diluted in $90 \mathrm{ml}$ of PBS and dilutions of the sample $\left(10^{-3}, 10^{-4}\right.$, and $\left.10^{-5}\right)$ were prepared. The diluted samples were spread on sterile Bushnell Haas agar plates. The medium (composition $\mathrm{MgSO}_{4} .7 \mathrm{H}_{2} \mathrm{O}[0.2 \mathrm{~g} / \mathrm{l}], \mathrm{K}_{2} \mathrm{HPO}_{4}[1.0 \mathrm{~g} / 1], \mathrm{KH}_{2} \mathrm{PO}_{4}[1.0 \mathrm{~g} / \mathrm{l}], \mathrm{FeCl}_{3}[0.05 \mathrm{~g} / \mathrm{l}], \mathrm{NH}_{4} \mathrm{NO}_{3}[1.0 \mathrm{~g} / \mathrm{l}], \mathrm{CaCl}_{2}[0.02 \mathrm{~g} / \mathrm{l}], \mathrm{pH}-$ 7.2) contains all the nutrients except a carbon source [8]. So the plates were supplemented with $1 \%$ filter sterilized petrol and incubated at $37^{\circ} \mathrm{C}$ for 2-3 weeks except the control plate. After incubation, the bacterial colonies grown on $\mathrm{BH}$ plates were characterized morphologically and biochemically.

\subsection{Determination of tolerance level to different petroleum concentration}

Different concentrations of petrol and kerosene $(1 \%, 2 \%, 4 \%$ and $8 \%)$ containing $\mathrm{BH}$ agar plates were inoculated with the isolated cultures and finally incubated at $37^{\circ} \mathrm{C}$ for 7 days. Tolerance to petrol and kerosene were observed by the ability of organisms to grow on $\mathrm{BH}$ agar plates containing the respective concentration of the hydrocarbons.

\subsection{Determination of activity of different hydrocarbon degrading enzymes in the isolates \\ 2.4.1. Laccase assay}

Laccase can catalyse the ring cleavage in aromatic compounds. So to assay laccase activity, sterile nutrient agar plates supplemented with $0.02 \%$ bromophenol blue were inoculated with the isolates and a control organism which is not petroleum degrading. The plates were incubated at $37^{\circ} \mathrm{C}$ for 24 hours. The change in the intensity of the blue colour of the plate due to the destruction of the ring structure of bromophenol blue around the growth of the organism was observed only around test isolates but not around the control organism.

\subsubsection{Monophenol oxidase or tyrosinase assay}

Tyrosinase catalyses the destruction of resonance structure of aromatic compounds by hydroxylation. To assay tyrosinase, sterile Nutrient Broth containing test tubes, each of which contains $0.1 \mathrm{mM}$ tyrosine were inoculated with the isolates separately. A control set was maintained for each isolate where the tyrosine was replaced by sterile water. Tyrosinase would be converted to its o-quinone derivative via dihydroxyphenylalanine, when subjected to tyrosinase, which cannot absorb light of $280 \mathrm{~nm}$ like tyrosinase. So tyrosinase activity can be estimated by the decrease in OD value at $280 \mathrm{~nm}$ in the test tube compared to the control set. To avoid the interference of $280 \mathrm{~nm}$ light absorbance of extracellular proteins, $0.1(\mathrm{~N}) \mathrm{NaOH}$ was used to degrade and coagulate the proteins, which can be separated by centrifugation before taking the optical density readings. Both test and control tubes were incubated at $37^{\circ} \mathrm{C}$ and $\mathrm{OD}$ reading were taken at day 0 , day 1 and day 3.

\subsubsection{Polyphenol oxidase or Catechol oxidase assay}

Catechol oxidase catalyzes the oxidation of ortho-diphenols into ortho-quinones with the reduction of molecular oxygen to water. To assay catechol oxidase, sterile Nutrient Broth supplemented with $0.1 \mathrm{mM}$ 
catechol were prepared, into which the isolates were inoculated separately. A control set was maintained for each isolate where the catechol was substituted by sterile water. Catechol or 1, 2-dihydroxybenzene, like other polyphenols, can form adduct with Folin ciocalteau, which can be stabilized by the addition of $\mathrm{Na}_{2} \mathrm{CO}_{3}$ solution, and this adduct can absorb light at $765 \mathrm{~nm}$. But quinone derivatives of catechol, produced after catechol oxidase reaction cannot form this adduct. So the catechol oxidase activity can be estimated by the decrease in OD value at $765 \mathrm{~nm}$ in the test set compared to the control set. Both test and control set tubes were incubated at $37^{\circ} \mathrm{C}$ and OD readings were taken in Day 0, Day 1 and Day 3.

\subsection{Estimation of $\mathrm{CO}_{2}$ evolution}

Microbial metabolism of petroleum products generate C2, C4 and C6 TCA intermediates, which is finally converted to $\mathrm{CO}_{2}$ and biomass. Thus incubating hydrocarbon degrading bacteria in a medium supplemented with hydrocarbon may produce $\mathrm{CO}_{2}$ as a by-product. So the measurement of $\mathrm{CO}_{2}$ liberated due to petroleum degradation, by observing the change in $\mathrm{pH}$ of $\mathrm{CO}_{2}$ - trap like $\mathrm{NaOH}$, can be very important tool to determine the rate of petroleum degradation. This test has been carried out for isolates ' 1 ' and ' 3 ' only, due to their efficient results in the previous experiments. Two BH agar medium containing flasks, supplemented with petrol, were then separately inoculated by isolate ' 1 ' and ' 3 '. In control set, no petrol was added. Small tubes containing freshly prepared $0.1(\mathrm{~N}) \mathrm{NaOH}$ were then hanged to trap the evolved $\mathrm{CO}_{2}$ inside the flasks, whose mouths were sealed with a rubber cork and incubated at $37^{\circ} \mathrm{C}$. After a week, when the microbial colonies start to develop, the $\mathrm{pH}$ of residual $\mathrm{NaOH}$ were determined by titrating it against $1(\mathrm{~N}) \mathrm{HCl}$.

\subsection{Study on the ability of the isolate ' 3 ' to colonize on metallic surface}

Most often it is found that, many of the hydrocarbon degrading bacteria forms biofilm on the metallic surface of the aeroplane fuel tank and thus damages it. So the ability to colonize on the metallic surface was studied. This study was done only for isolate ' 3 ' as this isolate had showed highest laccase, tyrosinase and catechol oxidase activity. In this study, at first the metallic fragments were sterilized and then inoculated with the isolate and placed in a moist chamber. After placing, they were incubated at $37^{\circ} \mathrm{Cfor}$ a week. A control set was also maintained were a metallic fragment without inoculation was incubated in a moist chamber. After incubation the test metallic fragment was observed via phase contrast microscopy for the presence of extracellular capsule like material on the surface of the microbial cells, which is normally found on the surface of the biofilm. Along with phase contrast microscopic observation, they were also checked for viability by inoculating them into a starch casein agar plate.

\subsection{Identification of isolate ' 3 '}

Due to having highest activity in different petroleum degrading enzyme and metal adhering ability isolate ' 3 ' was identified. Identification of the Isolate ' 3 ' was done by 3 approaches- morphological characterization, their ability to grow on specific selective medium and lastly by $16 \mathrm{~s}$ rDNA analysis. The microscopic analysis and colony morphology (powdery colonies) of isolate ' 3 ' showed a similar characteristic to that of the genus Actinomycetes. To confirm its nature, it was inoculated in an Actinomycetes selective media - Starch Casein Agar(composition-soluble starch[10g/l], casein[0.3g/l], $\mathrm{KNO}_{3}[2.0 \mathrm{~g} / \mathrm{l}], \mathrm{NaCl}[2.0 \mathrm{~g} / \mathrm{l}]$, $\mathrm{K}_{2} \mathrm{HPO}_{4}[2.0 \mathrm{~g} / \mathrm{l}], \mathrm{CaCO}_{3}[0.02 \mathrm{~g} / \mathrm{l}], \mathrm{MgSO}_{4} .7 \mathrm{H}_{2} \mathrm{O}[0.05 \mathrm{~g} / \mathrm{l}], \mathrm{FeSO}_{4} .7 \mathrm{H}_{2} \mathrm{O}[0.01 \mathrm{~g} / 1]$, Agar[20g/l], 50\% sea water, nystatin[50mg/l], benzyl penicillin[0.88mg/l], pH-7)and incubated at $37^{\circ} \mathrm{C}$ and the presence of growth was noted. Then for 16s rRNA sequencing of 'isolate 3' genomic DNA of the isolate was extracted and for analysis of the gene of 16s rRNA was amplified via Polymerase chain reaction. The PCR reaction was carried out using the following primer set- (i) forward primer 5' -AGAGTTTGATCMTGGCTCAG -3 ' (ii) reverse primer (5' CGGCTACCTTGTTACGACTT- 3 ')

The PCR fragments were then analyzed by $1.5 \%$ agarose gel electrophoresis using 100 bp DNA ladder and then visualized in gel Documentary system. After this amplification of the 16s rDNA were sequenced and it is compared to $16 \mathrm{~S}$ rDNA sequences available in the nucleotide databases of the GenBank using the basic local alignment search tool (BLAST) at the National Center for Biotechnology Information (NCBI), to determine the approximate phylogenetic position and percent homology scores to identify the isolate. And after comparing with other strains, a phylogenetic tree of Isolate ' 3 'was also prepared using Clustal Omega software.

\section{Results}

\subsection{Physical and chemical characterization of the soil sample}

The physical and chemical characteristics of the sample are given below (Table 1 and Table 2).

Table 1: Physical characteristics of the collected sample

\begin{tabular}{|c|c|}
\hline Colour & Brownish black colour. \\
\hline Texture & Grainy to smooth texture with certain gravels that were removed prior to analysis. \\
\hline Odour & An odour of petroleum emanates from the sample. \\
\hline
\end{tabular}


Table 2: Chemical characteristics of the collected sample:

\begin{tabular}{|c|c|}
\hline $\mathbf{p H}$ & 6.2 \\
\hline Electrical conductivity & 177.15 siemens \\
\hline
\end{tabular}

\subsection{Isolation of petroleum degrading bacteria}

Six different types of colonies were obtained from the BH agar plates containing $1 \%$ petrol these colonies were absent in the control plate, that lack the petrol. The isolated colonies were designated as Isolate 1 - Isolate 6.

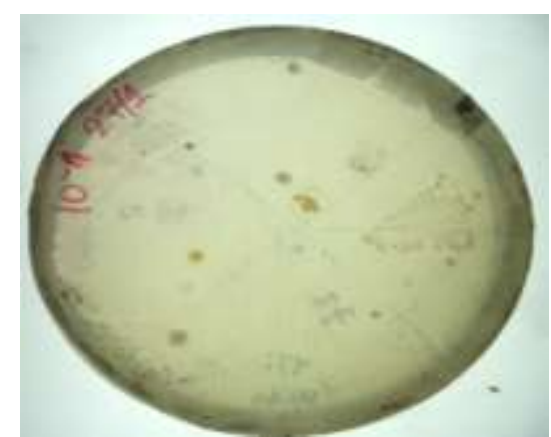

Figure 1: The BH plate showing the colonies of the isolates obtained on inoculating $10^{-4}$ dilution of soil suspension

\subsection{Morphological and biochemical characterization of the sample}

The morphological and biochemical characterization of the isolates are provided in Table 3 .

Table 3: Morphological and biochemical characterization of the isolates.

\begin{tabular}{|c|c|c|c|c|c|c|}
\hline \multirow{2}{*}{$\begin{array}{c}\text { Characterization } \\
\text { of the isolates }\end{array}$} & \multicolumn{6}{|c|}{ Designation of isolates } \\
\hline & 1 & 2 & 3 & 4 & 5 & 6 \\
\hline Morphology & $\begin{array}{c}\text { Smooth, } \\
\text { medium, } \\
\text { whitish round }\end{array}$ & $\begin{array}{c}\text { Small, pale } \\
\text { yellow, smooth, } \\
\text { irregularly shaped. }\end{array}$ & $\begin{array}{l}\text { Whitish, powdery, } \\
\text { rough, round } \\
\text { colonies. }\end{array}$ & $\begin{array}{c}\text { Yellowish, big, } \\
\text { smooth, round } \\
\text { colonies. }\end{array}$ & $\begin{array}{l}\text { Whitish, } \\
\text { smooth, small } \\
\text { irregularly } \\
\text { shaped. }\end{array}$ & $\begin{array}{l}\text { Reddish, } \\
\text { tiny, } \\
\text { smooth, } \\
\text { round. }\end{array}$ \\
\hline Gram character & $\mathrm{G}(+)$ & $\mathrm{G}(-)$ & $\mathrm{G}(+)$ & $\mathrm{G}(+)$ & $\mathrm{G}(-)$ & $\mathrm{G}(-)$ \\
\hline Indole Test & - & - & - & - & - & - \\
\hline Methyl Red & - & - & - & - & + & - \\
\hline Voges Proskauer & + & + & + & + & - & + \\
\hline Citrate Utilization & + & + & + & + & - & - \\
\hline Catalase & + & + & + & + & + & + \\
\hline Oxidase & - & + & + & - & + & + \\
\hline
\end{tabular}

('+' denotes poaitive result, whereas '-' denotes negative of result)

\subsection{Determination of tolerance level to different petrol and kerosene concentration}

The tolerance level of the isolates to different concentrations of petrol and kerosene was observed and provided in Table 4 and Table 5 respectively.

Table 4: Sensitivity profile of the isolates to different concentrations of petrol.

\begin{tabular}{|c|c|c|c|c|}
\hline Designation of isolates & \multicolumn{5}{|c|}{ Concentration of Petrol } \\
\cline { 2 - 5 } & $\mathbf{1 \%}$ & $\mathbf{2 \%}$ & $\mathbf{4 \%}$ & $\mathbf{8 \%}$ \\
\hline 1 & + & + & + & + \\
\hline 2 & + & + & + & - \\
\hline 3 & + & + & + & + \\
\hline 4 & + & + & + & + \\
\hline 5 & + & + & + & - \\
\hline 6 & + & + & - & - \\
\hline
\end{tabular}

(“+” denotes presence of growth, whereas “_"“denotes absence of growth)

Table 5: Sensitivity profile of the isolates to different concentrations of kerosene.

\begin{tabular}{|c|c|c|c|c|}
\hline \multirow{2}{*}{ Designation of isolates } & \multicolumn{4}{|c|}{ Concentration of Kerosene } \\
\cline { 2 - 5 } & $\mathbf{1 \%}$ & $\mathbf{2 \%}$ & $\mathbf{4 \%}$ & $\mathbf{8 \%}$ \\
\hline 1 & + & + & + & + \\
\hline 2 & + & + & + & + \\
\hline 3 & + & + & + & + \\
\hline 4 & + & + & + & + \\
\hline 5 & + & + & + & - \\
\hline 6 & + & + & + & - \\
\hline
\end{tabular}

("+" denotes presence of growth, whereas "_"ddenotes absence of growth) 


\subsection{Activity of different hydrocarbon degrading enzymes in the isolates}

\subsection{Laccase Assay}

Due to the laccase activity, discolouration was observed around colonies of isolate 1 and isolate 3 only, but the discolouration was not observed in case of other isolates.

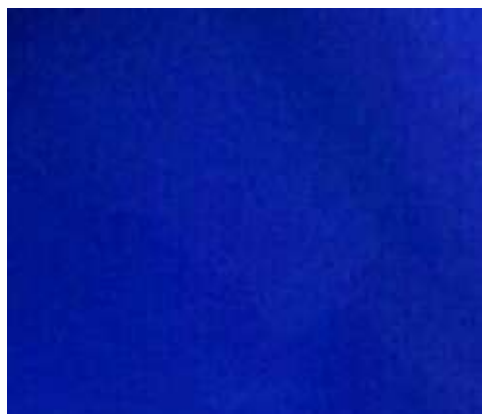

(A)

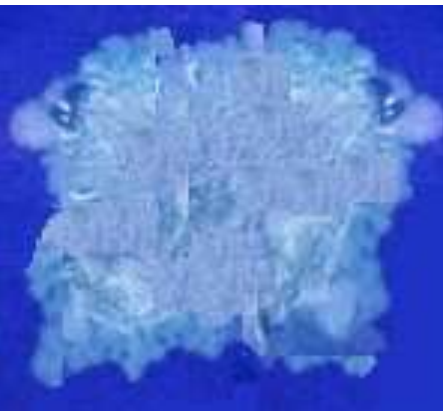

(B)

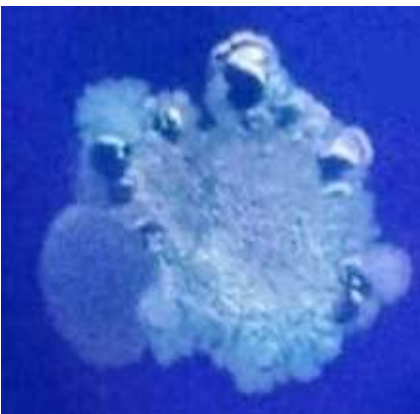

(C)

Figure 2: Observation of the Laccase assay where isolate 1 and 3 shows discolouration while other isolates do not show any change - (A) Original colour of the plate (B) Discolouration done by Isolate 1 (C) Discolouration done by Isolate 3

\subsubsection{Tyrosinase Assay}

In the span of three days the change in O.D. values at $280 \mathrm{~nm}$ were taken into account for the six isolates. It is noted that the O.D. values decreased subsequently owing to the fact that tyrosine's concentration decreased. The changes in the O.D. values at $280 \mathrm{~nm}$ are tabulated in the Table 6.

Table 6: The changes in O.D. values at $280 \mathrm{~nm}$ and tyrosinase activity of the isolates

\begin{tabular}{|c|c|c|c|c|}
\hline \multirow{2}{*}{$\begin{array}{c}\text { Designation of } \\
\text { isolates }\end{array}$} & \multicolumn{3}{|c|}{ O.D value at 280 nm } & Tyrosinase activity (O.D/ \\
\cline { 2 - 4 } Day)
\end{tabular}

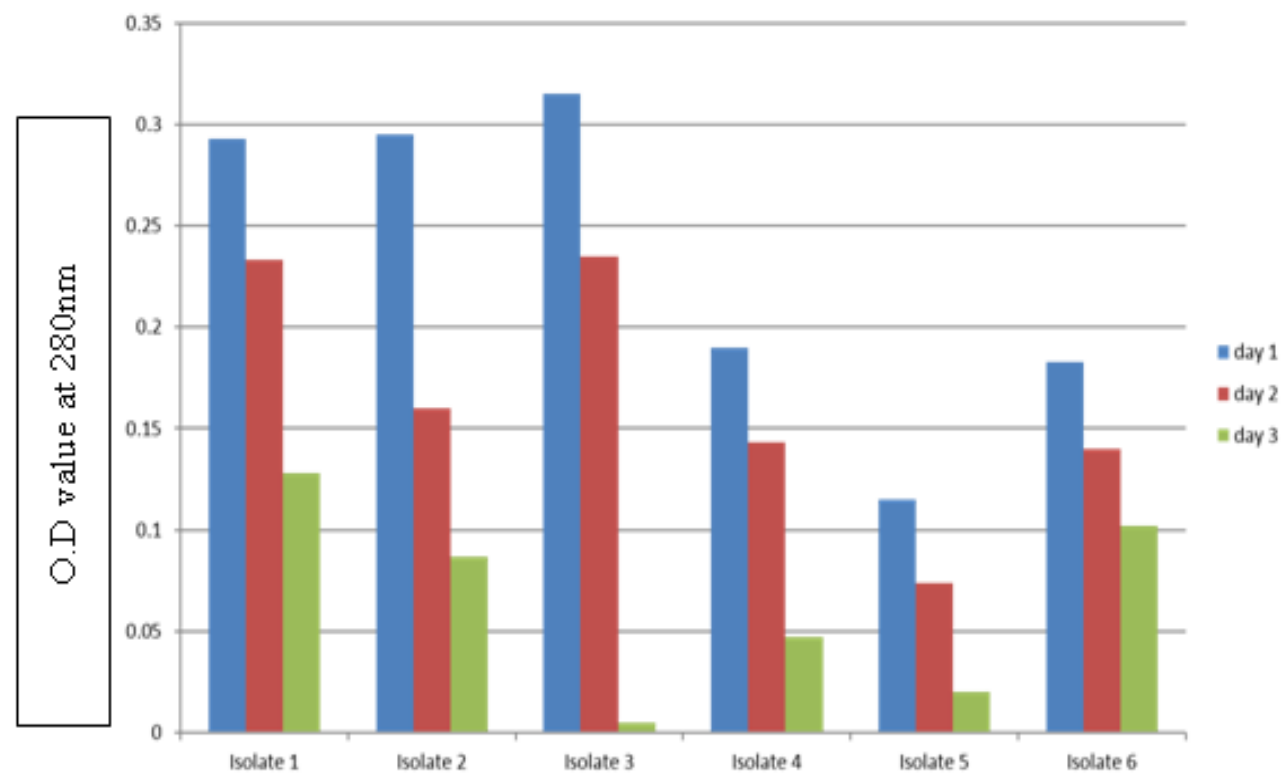

Figure 3- The graphical representation of the changes in the O.D. values in the reaction medium due to the tyrosinase activity of different isolates. Y-axis denotes the O.D. values of the test culture solutions at $280 \mathrm{~nm}$ and the $\mathrm{X}$-axis denotes the test isolates. 


\subsubsection{Catechol oxidase Assay}

In the span of three days, the change in O.D. values of the samples was observed at $765 \mathrm{~nm}$ for six isolates. It is noted that the O.D. values were decreased subsequently due to catechol oxidase activity of the isolates, which is responsible for the reduction in the concentration of the catechol, which reduces the amount of the catechol folin-ciocalteau adduct. The changes in the O.D. values at $765 \mathrm{~nm}$ were tabulated in the Table 7.

Table 7: The O.D. values of the isolates for catechol oxidase and catechol oxidase activity at $765 \mathrm{~nm}$.

\begin{tabular}{|c|c|c|c|c|}
\hline \multirow{2}{*}{$\begin{array}{c}\text { Designation of } \\
\text { isolates }\end{array}$} & \multicolumn{3}{|c|}{ O.D value at 765 nm } & \multirow{2}{*}{$\begin{array}{c}\text { Catechol oxidase } \\
\text { activity (O.D/ Day) }\end{array}$} \\
\cline { 2 - 4 } & Day 0 & Day 1 & Day 2 & 0.103 \\
\hline 1 & 0.582 & 0.475 & 0.376 & 0.135 \\
\hline 2 & 0.622 & 0.484 & 0.352 & 0.164 \\
\hline 3 & 0.653 & 0.432 & 0.325 & 0.122 \\
\hline 4 & 0.651 & 0.512 & 0.407 & 0.090 \\
\hline 5 & 0.619 & 0.547 & 0.439 & 0.077 \\
\hline 6 & 0.540 & 0.444 & 0.386 & \\
\hline
\end{tabular}

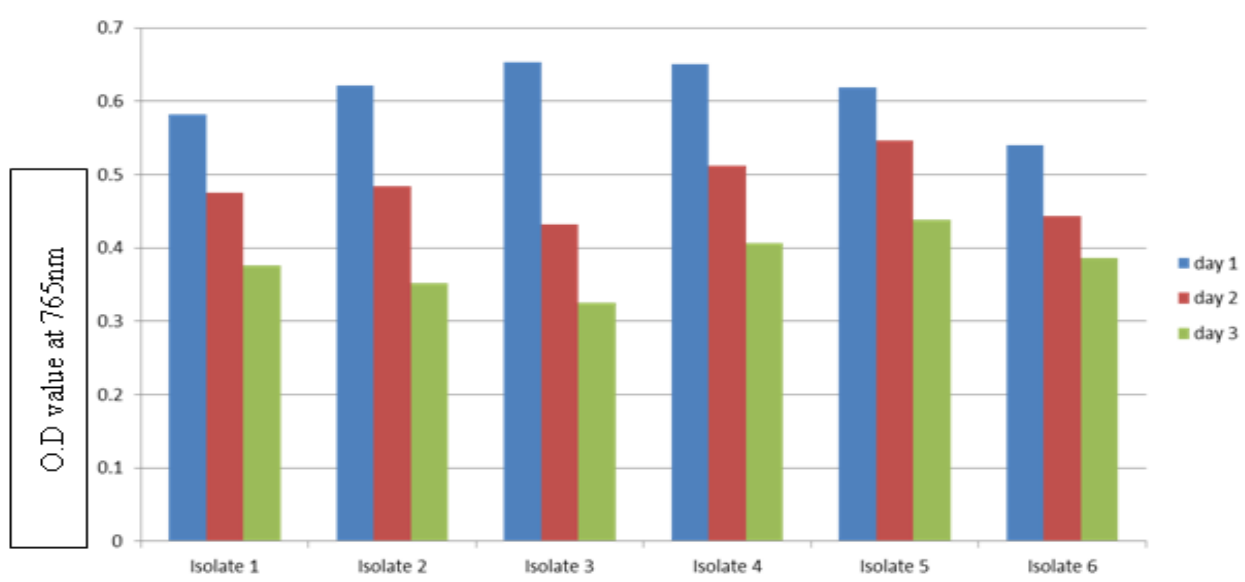

Figure 4: The graphical representation of the changes in the O.D. at $765 \mathrm{~nm}$ values in the reaction medium of catechol oxidase assay due to the catechol oxidase activity of different isolates. Y-axis represents the O.D. values of the test culture solutions at $765 \mathrm{~nm}$ and $\mathrm{X}$-axis represents the test isolates.

\subsection{Estimation of $\mathrm{CO}_{2}$ evolution}

The results of the $\mathrm{CO}_{2}$ evolution assay were provided in Table 8 .

Table 8: The amount of $\mathrm{CO}_{2}$ evolved for isolates 1 and 3.

\begin{tabular}{|c|c|c|}
\hline Culture & Vol of $1(\mathrm{~N}) \mathrm{HCl}$ utilized $(\mathrm{ml})$ & Amount of $\mathrm{CO}_{2}$ Evolved $(\mathrm{ml})$ \\
\hline Control (3) & 12.5 & - \\
\hline Test Culture 1 & 9.1 & 7 \\
\hline Test Culture 3 & 10.75 & 4 \\
\hline
\end{tabular}

The amount of $\mathrm{HCl}$ utilized is inversely proportional to the amount of $\mathrm{CO}_{2}$ produced. Thus isolate ' 1 ' produced more $\mathrm{CO}_{2}$ than isolate ' 3 ' and it can be calculated that isolate ' 1 ' and ' 3 ' have produced $4 \mathrm{ml}$ and $7 \mathrm{ml}$ of $\mathrm{CO}_{2}$ respectively in comparison with control set in the course of incubation period.

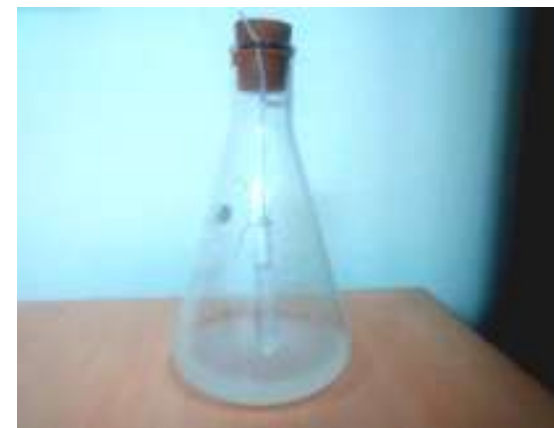

Figure 5: Reaction setup of $\mathrm{CO}_{2}$ evolution assay showing the hanging tube containing $0.1(\mathrm{~N}) \mathrm{NaOH}$ 


\subsection{Metallic surface colonizing study}

After the incubation, formation of biofilm was observed on the surface of the metallic fragment. When it was observed under phase contrast microscopy, white halos were found on the surface of the microorganism, which corresponds to extracellular capsule like material. And when this biofilm was tested for its viability, it was found that the organism remained viable and can grow on starch casein agar plate.

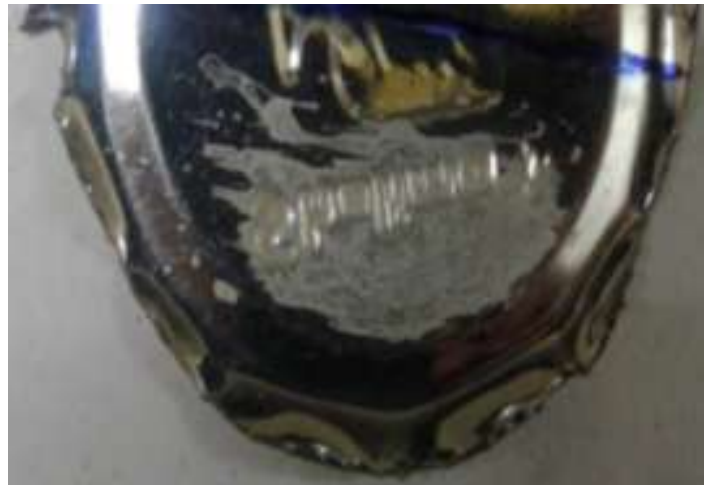

(A)

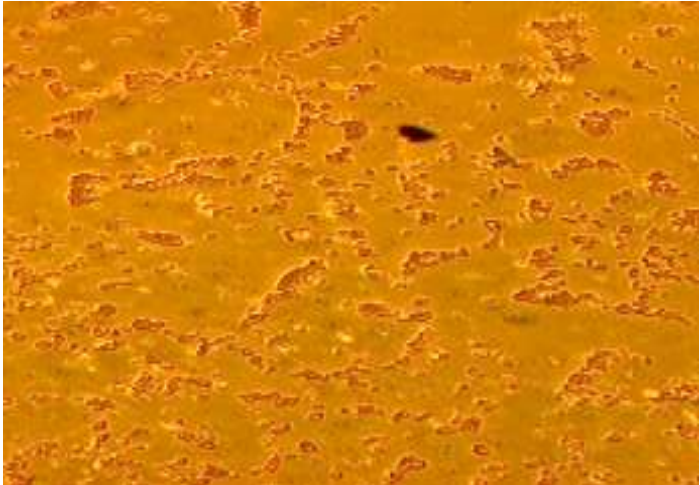

(B)

Figure 6: (A) Formation of biofilm on the surface of metallic fragment by the formation of extracellular polysaccharides, like capsules after 7 days of incubation. (B) Halos surrounding the organisms produced after 7 days of incubation, which corresponds to presence of capsules required for biofilm formation on the surface of metals

\subsection{Identification of isolate ' 3 '}

When the isolate ' 3 ' was tested for its ability to grow in starch casein agar plate, growth was observed on the agar plate. PCR amplification using the above mentioned primers for the 16s rDNA was also observed and the amplification gave a band of less than 1500bp DNA fragment. From the sequencing of the rDNA and its alignment in BLAST programme, it was identified as Steptomyces bacillaris S4BW2 and it shows $100 \%$ similarity in the alignment.

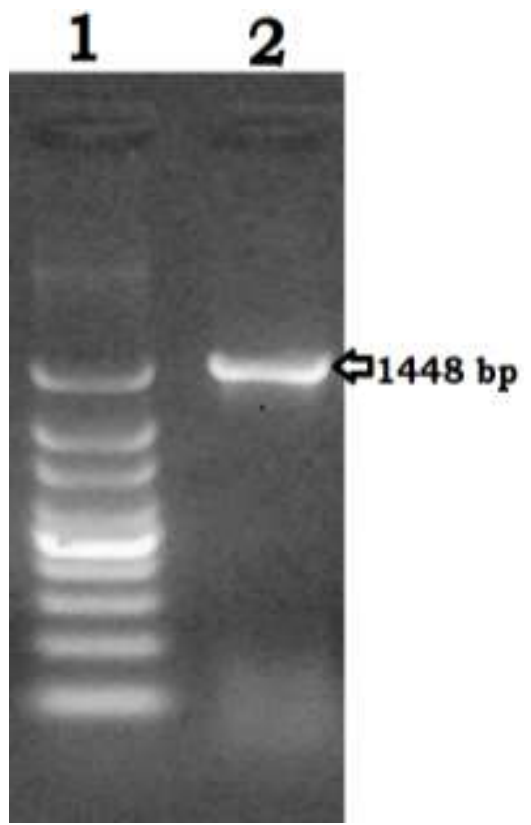

Figure 7: $0.8 \%$ Agarose gel showing single $1.5 \mathrm{~kb}$ of $16 \mathrm{~S} r D N A$ amplicon. Lane 1: $100 \mathrm{bp}$ DNA ladder; Lane 2: $16 \mathrm{~S}$ rDNA amplicon

Table 9: BLAST result of 16s rDNA gene sequence of Isolate 3.

\begin{tabular}{|c|c|c|c|c|c|}
\hline Designation of the isolate & BLAST Match & Strain & rDNA & Accession No. & Identity \\
\hline Isolate 3 & Steptomyces bacillaris & S4BW2 & 1048 bp & JN400100.1 & $100 \%$ \\
\hline
\end{tabular}



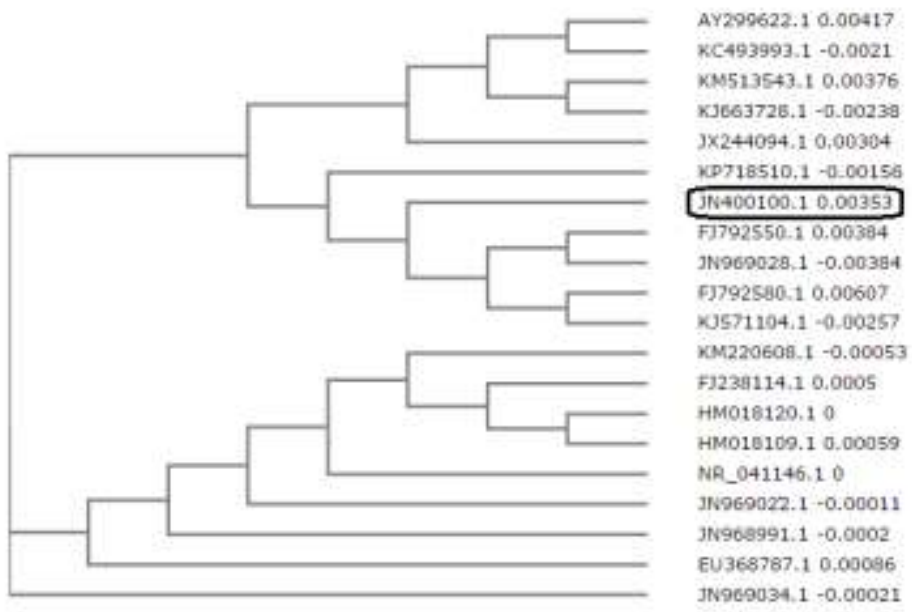

Figure 9: Phylogenetic Tree of Isolate ' 3 ' obtained after analyzing the BLAST result

\section{Conclusion and Discussion}

The samples were collected from oil contaminated sites near petrol pump of petrochemical industries and it was transferred to the laboratory in sterile condition for analysis. Physical and chemical characterization of the sample was performed followed by isolation of petroleum degrading bacteria from the sample. In order to isolate a mineral based media, called Bushnell Hass $(\mathrm{BH})$ media was used which lack any carbon source [9]. And this media was supplemented with petrol as the sole carbon source. Thus only 6 types of colonies were obtained which grew on those plates thereby indicating their ability to degrade petroleum [10].Characterization of the six isolates were performed which included gram character [11], biochemical tests such as IMViC tests, oxidase test, catalase test [12]. Sensitivity assay of different concentration of petrol and kerosene were performed in which isolate 1 and 3 showed dense growth at maximum concentration of petroleum and kerosene. Various hydrocarbon degrading enzymes assay were also performed for such as laccase assay [13], tyrosinase [14]. Isolate 3 was shown to be more efficient in all of the enzyme assay mentioned above. Quantitative analysis of $\mathrm{CO}_{2}$ was performed in the presence and absence of petroleum and isolate 1 produced more $\mathrm{CO}_{2}$ than isolate 3. Since the isolated petroleum degrading microorganisms are able to colonize on metal surfaces by producing biofilm, it can reduce the fuel consumptions of the automobiles by surviving on the metal surface of petroleum containers contaminated with isolate 3 or similar organism. Isolate 3 was grown on a selective media i.e. Starch Casein Agar, in order to detect the nature of it. This media is specific for Actinomycetes sp. And growing isolate 3 in this media showed positive result. As isolate 3 showed most efficient results 16srRNA analysis was performed and the result is Streptomyces bacillaris.

Review of literature reveals that individually extensive work has been done in isolating petrol degrading bacterial isolates from oil polluted soil. In the study carried out by Jyothi K et al. (2012) [1], seven petroleum degrading strains were isolated from three soil samples near petrol and diesal pumps in Husain Sagar Lake, Hyderabad and these bacterial strains showed 99\% similarity in 16s rRNA sequence with Staphylococcus aureus,Micrococcus luteus, Lactobaciluus acidophilus, Corynebacterium xerosis,Neisseria flavescens, Bacillus megaterium and Bacillus cereus respectively.

In the study carried out by S. K. Panda et. al. [11], oil contaminated soil, sea water and sediment samples were collected from old oil jetty of Paradip port, Orissa. The level of petroleum hydrocarbon degradation was determined by gravimetric assay at each 5 days interval and one potent gram negative bacillus bacteria was isolated on the basis of petroleum hydrocarbon degradation efficiency and identified as Pseudomonas sp. The bacterial strain had shown $49.93 \%$ of diesel oil degradation in 20days against $0.5 \%$ of diesel in $100 \mathrm{ml}$ BHM.

In the study by Mamitha Kumar Subathra et. al. [14], sediment samples were collected from area surrounding Ennore creek and screened for hydrocarbon degrading bacteria of which three efficient crude oil bacterial isolates Bacillus subtilis I1, Pseudomonas aeruginosa I5 and Pseudomonas putida I8 were identified both biochemically and phylogenetically. The quantitative analysis of biodegradation was carried out gravimetrically and highest degradation rate, 55\% was recorded by Pseudomonas aeruginosa I5 isolate.

In the study undertaken by Tazeena Hassan Islam et. al. [7], petroleum tolerant and degrading bacteria were isolated from different oil-contaminated soil and water samples. From three soil samples and two water samples, a total of nine bacterial strains were isolated capable of degrading petrol, kerosene and diesel with varying tolerance capacities. The isolates were identified by using standard biochemical tests and morphological 
studies, and it was determined that these strains belong to six bacterial genera e.g.,Staphylococcus, Micrococcus, Streptococcus, Bacillus, Klebsiella and Corynebacterium. The isolated Staphylococcus spp. were found to be the most tolerant isolate withstanding as high as $7 \%$ petroleum. The others also exhibit tolerance to varying concentrations of petroleum. All these isolates were able to degrade petroleum completely and produced $\mathrm{CO}_{2}$ within 7 days, with a few exceptions for Bacillus sp. and Klebsiella sp. which required 15 days for complete degradation of kerosene. These isolates seemed to have potential for bioremediation of oil contaminated soil and water.

\section{References}

[1] J.G. Leahy, and R.R. Colwell, Microbial Degradation of Hydrocarbons in the Environment, Microbiological Reviews, 54(3), 1990, 305-315

[2] M. Viñas, J. Sabaté , M.J. Espuny, and A.M. Solanas, Bacterial Community Dynamics and Polycyclic Aromatic Hydrocarbon Degradation during Bioremediation of Heavily Creosote-Contaminated Soil, Applied and Environmental Microbiology, 71(11), 2005, 7008-7018.

[3] T.H. Islam, B. Ghosh, M.H. Magnet, K. Fatema, S. Akter, M.A.R. Khan, and S. Datta, Isolation and identification of petroleum degrading bacteria from oil contaminated soil \& water and assessment of their potentially in bioremediation, IOSR Journal of Environmental Science, Toxicology And Food technology, 5(2), 2013, 55-58.

[4] A.I. Okoh, Biodegradation alternative in the cleanup of petroleum hydrocarbon pollutants, Biotechnology and Molecular Biology Review, 1(2), 2006, 38-50.

[5] D. Elliot, Power resources, Technology, Environmental aspect, social aspects (Routledge, London 1997)

[6] G.O. Adams, P.T. Fufeyin, S.E. Okoroz, and I. Ehinomen, Bioremediation, Biostimulation and Bioaugmention: A Review, International Journal of Environmental Bioremediation \& Biodegradation, 3(1) 2015: 28-39.

[7] M. Dua, A. Singh, N. Sathunathan, and A.K. Johri, Biotechnology and Bioremediation: Success and Limitations, Appl. Microbiol. Biotechnol, 59(2-3), 2002, 143- 152

[8] L.D. Bushnell, H.F. Haas, The utilization of certain hydrocarbons by microorganisms, J. Bacteriol., 41, 1941, 653-673.

[9] Jyothi. K., Babu, K.S. Babu,, N. Clara. K., and A. Kashyap, Identification and Isolation of Hydrocarbon Degrading Bacteria by Molecular Characterization, Helix, 2, 2012, 105-111.

[10] S.J. Varjani, D.P. Rana, S. Bateja, and V.N. Upasani, Isolation and Screening for Hydrocarbon Utilizing Bacteria (HUB) from Petroleum Samples, International Journal of Current Microbiology and Applied Science, 2(4), 2013, 48-60.

[11] M.K. Subathra, G. Immanuel, and A.H. Suresh, Isolation and Identification of hydrocarbon degrading bacteria from Ennore creek, Bioinformation, 9(3), 2013, 150-157.

[12] C.S. Karigar, and S.S. Rao, Role of Microbial Enzymes in the Bioremediation of Pollutants: A Review, Enzyme Research Article ID 805187,2011

[13] A.K. Haritash and C.P. Kaushik, Biodegradation aspects of Polycyclic Aromatic Hydrocarbons (PAHs), J Hazard Mater. 169(1-3), 2009, 1-15.

[14] S.K. Panda, R.N. Kar, and C.R. Panda, Isolation and identification of Petroleum degrading microorganisms from oil contaminated environment, International Journal of Environmental Sciences, 3(5), 2013, 1314-1321. 